\title{
Helen Salisbury: Whose record is it anyway?
}

\author{
Helen Salisbury GP \\ Oxford
}

From April 2020, patients will have full online access to prospective data from their patient record, including the free text of consultations. While I welcome the move towards shared medicine and the openness that it signals, I have misgivings and concerns that GPs are not prepared for this change.

When I first started in general practice, computers were fairly new. Although current consultations were documented on screen, staff would pull out all paper files for patients booked into a clinic, as we'd often need to look up previous visits or hospital records. One of my colleagues had such illegible handwriting that I mostly relied on the patients' memories. The notes were a scanty shorthand serving as an aide memoire for the next consultation and were often intelligible only to the doctor who had written them.

These days the medical record serves many functions: in addition to reminding the usual doctor (or informing a new one) about the patient's history, the codes embedded in it are extracted for multiple purposes. They inform payments to practices through the Quality and Outcomes Framework in the UK and through billing in other countries. Data are used for calculating risk scores, for service planning, and to enable research by academics or drug companies, unless patients actively opt out. ${ }^{1}$

Patients have always been able to request to see their medical record, and doctors are frequently reminded that what they write should be clear, accurate, factual, and legible. ${ }^{2}$ Online patient access to limited parts of the medical record has been available for a few years, to help patients order prescriptions and check their results without needing to call the surgery.

However, medical notes are not just a record of patient consultations but are also littered with third party contacts such as, "Don't tell Dad I rang you, but please, can you talk to him about his drinking?" or "soft concerns" about child safeguarding. From now on we need to be scrupulous in electronically hiding such contacts. In theory, this online access is retrospective back to April 2019, and every record will need to be read and redacted before this can happen.

I'm worried about the safety of domestic abuse victims who may be coerced into sharing their medical record, but I'm also concerned about what might not be written in the notes in future, the things we'll leave out for fear of upset. Observations about the mismatch between symptoms and signs, concerns about self-care, possible but unlikely diagnoses that I should check up on-these all feature in my GP notes but would need a whole load of explaining to patients. If I don't have the time to explain my every thought (and it may not be appropriate to do so) I won't write it down at all in future.

I don't know whether the benefit of complete access outweighs the loss of richness in the notes that will follow, but I wish I'd been party to the decision making around this policy.

\section{Competing interests: See www.bmj.com/about-bmj/freelance-contributors.}

Provenance and peer review: Commissioned; not externally peer reviewed.

1 NHS. Sharing your health records. 24 May 2018. https://www.nhs.uk/using-the-nhs/aboutthe-nhs/sharing-your-health-records/.

2 BMA. Access to health records. 2019. https://www.bma.org.uk/advice/employment/ethics/ confidentiality-and-health-records/access-to-health-records.

Published by the BMJ Publishing Group Limited. For permission to use (where not already granted under a licence) please go to http://group.bmj.com/group/rights-licensing/ permissions 